\title{
Cloud Computing: Issues and risks of Embracing the Cloud in a Business Environment
}

\author{
Shafat Khan ${ }^{*}$ \\ IT Faculty, COMPILER - Institute of Computer Science, Srinagar J\&K India
}

Received: 01 February 2019; Accepted: 25 April 2019; Published: 08 July 2019

\begin{abstract}
Over the latest couple of years, cloud computing has created from being a promising business thought to one of the rapidly creating portions of the IT business. Despite the boom of cloud and the numerous favorable circumstances, for example, financial advantage, rapid elastic resource pool, and on-demand benefit, endeavor clients are yet hesitant to send their business in the cloud and the paradigm likewise makes difficulties for the two clients and suppliers. An absence of fitting answers for such difficulties may cause dangers, which may exceed the normal advantages of utilizing the paradigm. To address the difficulties and related dangers, an orderly hazard the board practice is vital that guides clients dissect the two advantages and dangers identified with cloud-based frameworks. The point of this paper is to provide better comprehension to configuration difficulties of cloud computing and distinguish essential research heading in such manner as this is an expanding area.
\end{abstract}

Index Terms: Cloud computing, Data center, Risks, Challenges, Security, Business.

(C) 2019 Published by MECS Publisher. Selection and/or peer review under responsibility of the Research Association of Mode rn Education and Computer Science

\section{Introduction}

Cloud computing has as of late developed as a convincing paradigm for overseeing and conveying administrations over the web. The ascent of Cloud Computing is quickly changing the scene of data innovation, and at last, transforming the long-held guarantee of utility processing into a reality. It draws in entrepreneurs because of its capacity to take out the provisioning plan overhead and enables the business

* Corresponding author.

E-mail address: contactdrshafat@gmail.com 
to begin from the little scale and powerfully increment their assets at the same time with the expansion of their administration request [1]. Cloud computing guarantees to convey dependable administrations through cutting-edge data centers based on the virtualized process and capacity advancements. Clients will have the capacity to get to applications and information from a Cloud anyplace on the planet following the compensation as-you-go (PAYG) money-related model.

Cloud computing is a promising business idea that enables organizations to expand IT limit progressively without putting more in a new framework, staff preparing, and authorizing of new programming. The paradigm gives adaptability both as far as conceivable conveyance models, i.e., IAAS, PAAS, and SAAS and as far as conceivable organization models, i.e., private, public, hybrid, or community. It is less demanding to convey, keep up, and refresh programming in the cloud contrasted with the end-client machine.

This paper will examine the utilization of cloud computing and how cloud computing innovation centers around conveying genuine incentive to the business. Section II illustrates a brief literature review followed by Section III which provides an overview of Cloud Computing with its definition, characteristics, brief benefits and drawback and explains the layers and types of clouds. Section IV will discuss the Risks and Issues to Cloud Computing embracing in the Enterprise and finally finds the Cloud challenge declined from last few years through Rights' Scale. Finally, Section V concludes by outlining the contribution of this paper.

\section{Related Work}

Like any innovation, it makes new chances yet, in addition, presents dangers. Islam et al [2] expounded the instance of cloud computing, numerous difficulties are identified with security, protection, and control of information and assets. Such difficulties can cause potential dangers, which may exceed the normal advantages. Aggressors could take clients' protected innovation and other touchy data that is put away handled and oversaw in the cloud. It is critical to consider those viewpoints that may cause chances before clients to choose whether to move their frameworks, administrations, applications, as well as information to the cloud. Understanding security and protection dangers and discovering answers to control these dangers is a basic issue for the accomplishment of cloud computing paradigm [3].

Al-Mascati et al. [4] recognized the basic achievement factors which influence the cloud computing appropriation in Oman and contrast the outcomes and past investigations led in different nations, to more likely comprehend the circumstance of the selection of cloud computing inside organizations in Oman. To guarantee fruitful reception of cloud computing there are numerous variables which impact such appropriation, they have inspected 14 factors inside the oil and gas organizations in Oman and found that 12 of the relating theories are upheld. It was discovered that the best factors influencing the cloud computing appropriation are specialist co-ops bolster, the lacking telecom administrations, money-saving advantages, top administration support, and arrangement trial ability.

\section{Cloud Computing: An Overview}

As per the NIST (National Institute of Standards and Technology) Mell et al. [5], "Cloud computing is a model representation for authorizing helpful, omnipresent, on-request orchestrate access to a common pool of configurable enlisting assets (e.g., stockpiling, frameworks, servers, administrations, and applications) that can be immediately provisioned and dispensed with extraneous administration endeavour or specialist organization cooperation." Cloud computing has five vital attributes that separate them from different types of shared processing [5]. They are:

On-demand self-benefit: Any consumer can get the processing capacities as required, with none too insignificant human intercession 
Accessibility: All cloud-based administrations are accessible over the system and can be gotten to utilizing different system empowered gadgets

Elasticity: Cloud computing assets enlarge or compact to nearly coordinate the genuine necessities for an association

Pay-per-use: The administrations devoured on the cloud are estimated and charged on an as-you-use premise without a gigantic forthright duty

Resource pooling: Resources possessed by the seller are pooled and apportioned among numerous clients giving efficiencies of scale.

As shown in Fig. 1., cloud framework is an umbrella which covers both the equipment and programming essential for a day in and day out pay-as-you-go benefit. The client gets to data online in a day in and day out an arrangement from an assortment of gadgets - laptop, printer, PC, tablet, and cell phone [6].

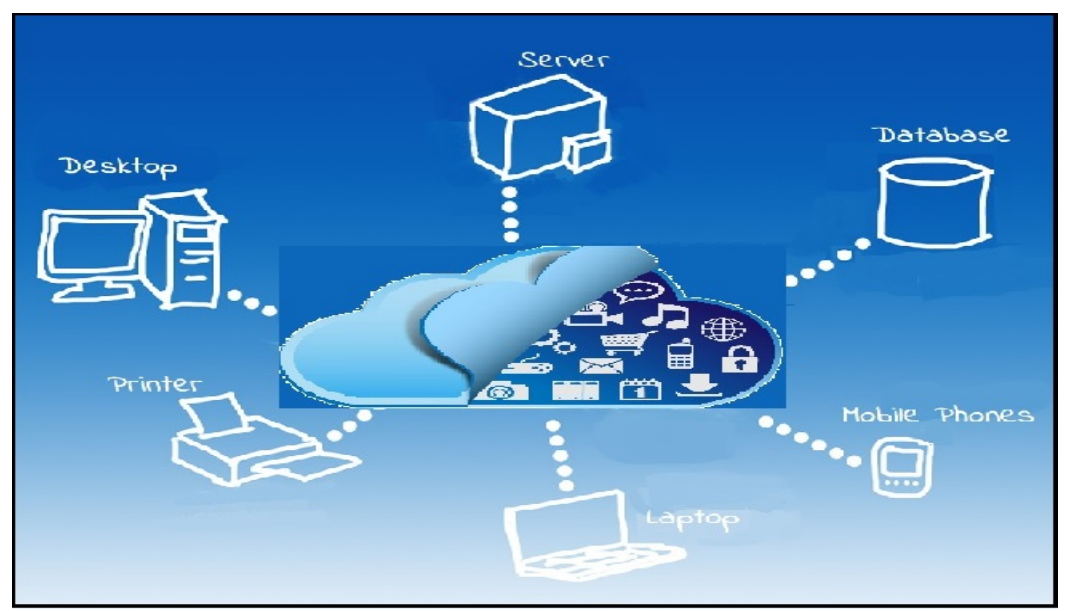

Fig. 1. Cloud infrastructure umbrella of different accessing devices

Cloud computing has its own arrangement of points of interest and inconveniences. The advantages of cloud computing incorporate operational adaptability and additionally the most favorable circumstances of shared assets. Vasiljeva et al. [7] uncovered the most esteemed advantages of cloud computing that expansion business readiness. Cloud computing has use based valuing which disposes of high capital costs on innovation and gives associations the adaptability to scale here and there relying upon their need. It additionally offers associations the chance to investigate regions, for example, examination, coordinated effort and so forth. Be that as it may, there are huge worries regarding the reception of cloud computing. Worries concerning cloud computing incorporate security of touchy and basic information. Associations on the cloud confront issues, for example, loss of power over vital information, blackouts, constrained transfer speed for information serious applications and security breaks prompting loss of touchy information [8,9]. Cloud computing is yet developing and has its very own arrangement of characteristic dangers [10]. Therefore, receiving the cloud requires cautious pondering and soundness as far as authoritative technique and cloud contributions.

\subsection{Layers and types of cloud}

Cloud computing administrations are separated into three classes, as indicated by the reflection dimension of the ability gave and the administration model of suppliers, namely:(1) Infrastructure as a Service, (2) 
Platform as a Service, and (3) Software as a Service [5]. Fig. 2. delineates the layered association of the cloud stack from physical framework to applications.

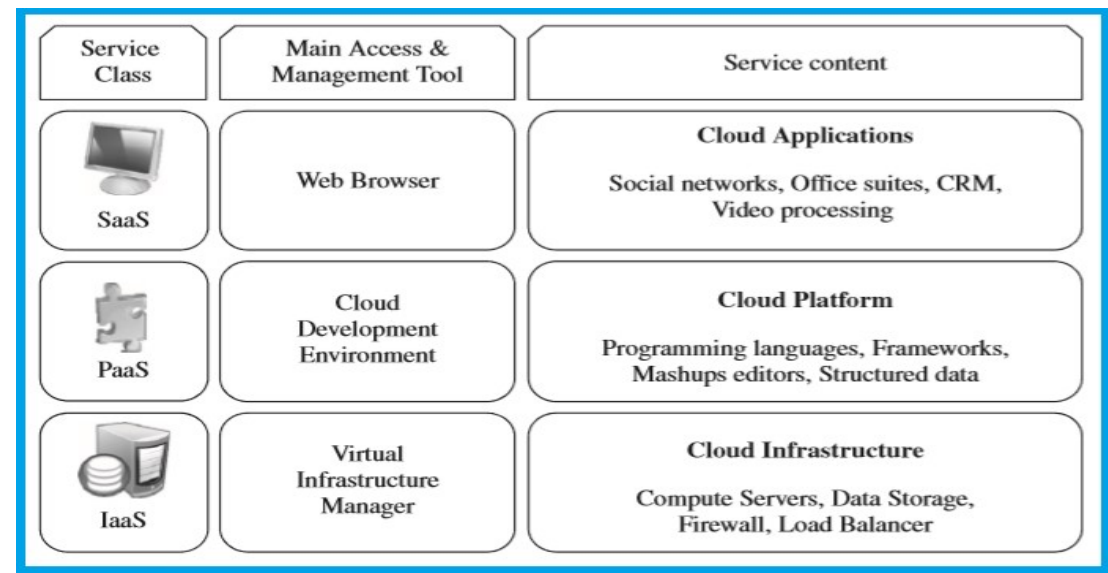

Fig. 2. The cloud computing service model stack [13]

\subsubsection{Infrastructure as a Service}

Offering effective assets (calculation, stockpiling, and correspondence) on interest is referred to as Infrastructure as a Service (IaaS) [11]. A cloud framework empowers on-request provisioning of servers running a few decisions of working frameworks, and a redid programming stack. IaaS services are the base layer of cloud computing systems [12].

Amazon Web Services essentially offers IaaS, which because of its EC2 benefit implies offering VMs with a product stack that can be redone like how a common physical server would be modified. Clients are offered benefits to play out various exercises to the server, for example, beginning and ceasing it, redoing it by introducing programming bundles, joining virtual circles to it, and configuring access authorizations and firewalls rules.

\subsubsection{Platform as a Service}

Notwithstanding framework arranged clouds that give crude processing and capacity benefits, another methodology is to offer a more elevated amount of reflection to make a cloud effectively programmable, referred to as Platform as a Service (PaaS). A cloud stage offers a domain on which engineers make and send applications and don't really need to know what number of processors or how much memory that applications will utilize. Also, various programming models and concentrated administrations (e.g., information access, confirmation, and installments) are offered as building squares to new applications [11]. Google AppEngine, a case of Platform as a Service, offers a versatile domain for creating and facilitating Web applications, which ought to be written in specific programming dialects, for example, Python or Java, and utilize the administrations' own exclusive organized question information store.

\subsubsection{Software as a Service}


Applications dwell on the elevated point of the cloud pyramid. Services given by this layer can be gotten to by end clients through Web entries. Accordingly, buyers are progressively moving from privately introduced PC projects to online programming administrations that offer the equivalent practically. Customary work area applications, for example, word handling and the spreadsheet would now be able to be gotten to as an administration in the Web [11]. This model of conveying applications, referred to as Software as a Service (SaaS), lightens the weight of programming support for clients and simplifies improvement and testing for suppliers [14]. Salesforce.com, which depends on the SaaS display, offers business profitability applications (CRM) that dwell totally on their servers, enabling clients to modify and get to applications on interest.

\subsubsection{Deployment Models}

Even though cloud computing has risen essentially from the presence of public figuring utilities, other deployment models, with varieties in physical area and dissemination, have been embraced. In this sense, paying little mind to its administration class, a cloud can be categorized as private, public, hybrid, or community [5] dependent on a model of arrangement as appeared in Fig 3.

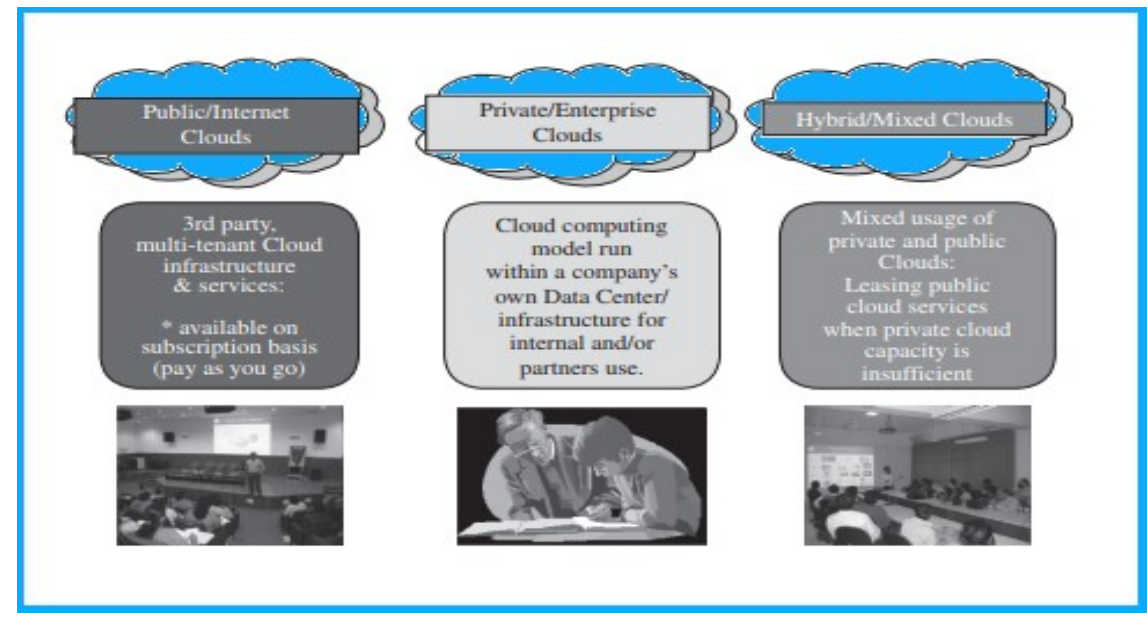

Fig. 3. Types of clouds build on deployment models [13]

Armbrust et al. [15] suggests definitions for public cloud as a "cloud influenced accessible in a pay-as-you-go mechanism to the widespread popular" and private cloud as "inside data center of a business or other association, not made accessible to the widespread general." In many cases, building up a private cloud implies rebuilding a current foundation by including effective and cloud-like gatherings. This enables clients to communicate with the neighborhood data center while encountering similar focal points of public clouds, most prominently self-benefit interface, special access to virtual servers, and per-use metering and charging. A community cloud is "shared by a couple of affiliations and support a specific organize that has shared concerns (e.g., security necessities, arrangement, mission, and consistency contemplations) [5]." A hybrid cloud takes to realization when a private cloud is improved with figuring limit from public clouds [11]. The methodology of briefly leasing ability to manage projection in load, known as "cloud- impacting " [29]. 


\section{Issues and threats to Cloud Computing enfolding in the Enterprise}

All Before considering cloud computing innovation, it is essential to comprehend the risks included while moving a business into the cloud. We should complete a hazard evaluation process before any control is given over to a specialist provider. Regardless of the underlying achievement and prevalence of the cloud computing paradigm and the broad accessibility of suppliers and apparatuses, a critical number of difficulties and risks are characteristic to this new model of registering [29]. Suppliers, designers, and end clients must think about these difficulties and risks to take great favorable position of cloud computing. There are a few snags with cloud computing, hindrances that can upset an association's reception of cloud and moderate the business movement toward cloud-based business activities [16]. The accompanying segment abridges these challenges:

\subsection{Security, Privacy and Trust}

Because cloud computing speaks to another figuring model, there is a lot of vulnerability about how security at all dimensions (e.g., arrange, host, application, and information levels) can be accomplished. That vulnerability has reliably driven data officials to express that security is their main worry with cloud computing. The capacity of cloud computing to sufficiently address security directions has been raised doubt about [13]. Organizations today confront various diverse necessities attempting to secure the protection of people's data, and it isn't clear (i.e., not yet settled) regardless of whether the cloud computing model gives satisfactory assurance of such data, or whether associations will be found infringing upon directions because of this new model. Security and assurance impact the entire cloud computing stack since there is a tremendous use of untouchable organizations and structures that are used to have fundamental data or to perform essential exercises. In this circumstance, the trust toward suppliers is basic to guarantee the ideal dimension of protection for applications encouraged in the cloud [17]. Lawful and administrative issues additionally require consideration. At the point when information is moved into the Cloud, suppliers may find them anyplace on the planet. The physical area of data centers decides the arrangement of laws that can be connected to the administration of information. For instance, explicit cryptography systems couldn't be utilized claiming they are not permitted in a few nations. Also, national laws can force that delicate information, for example, quiet wellbeing records, are to be put away inside national fringes.

The cloud is, by its tendency, an open and shared an asset. Sending information on a freely available correspondence framework have the peril of digital aggressors tapping the correspondence line and taking or tainting information from circle stockpiling. Three of the best cloud security issues confronting private ventures are lawful issues, consistency, and loss of authority over information Gonzalez et al. [18].

\subsection{Lack of Time and Sufficient Resources}

An absence of enough time is likewise a noteworthy obstacle to a fast appropriation of cloud computing in the venture. Private companies are regularly understaffed and overextended [19], leaving next to no slack time to execute new activities. Even though cloud computing could bring a private company significant advantages, execution is frequently passed on because of an absence of time for the company's pioneers to considerably think about the prospect.

An absence of preparing/skill is one of the greatest obstacles to a fast selection of cloud computing in the organization. Entrepreneurs will in general settle on choices in confinement without the advantage of guidance from skillful IT experts Feltham et al. [20]. Such firms frequently don't have propelled IT bolster staff in-house, and it is uncommon that entrepreneurs digress from isolated basic leadership to tune in to the 
exhortation of outside IT experts. It is additionally the situation that private ventures regularly don't have the budgetary assets to procure propelled IT experts in-house.

\subsection{Availability, Fault-Tolerance, and Disaster Recovery, Governance and QoS (Quality of Service) through Privacy agreement (PA) and SLA}

It is ordinary that customers will have certain suppositions with respect to the organization level to be given once their applications are moved to the cloud. These desires consolidate the openness of the organization, its general execution, and what measures are to be taken when something turns out severely in the system or its parts. In summary, customers search for a certification before they can undoubtedly move their business to the cloud. SLAs, that incorporate QoS necessities, must be preferably set up among clients and cloud computing suppliers to go about as a guarantee. An SLA determines the subtleties of the administration to be given, including accessibility and execution ensures. Furthermore, measurements must be settled upon by all gatherings, and punishments for disregarding the desires should likewise be endorsed. A basic arrangement of potential cloud hindrances incorporate administration, service level agreements (SLA), and by and large nature of administration (QoS) affirmation. Much as administration overwhelms the SOA dialog in guaranteeing fitting end-to-end administration over the IT and administrations lifecycle in the help of SOA activities, administration for cloud should likewise incorporate this. You should have appropriate assertions set up with your specialist organizations before administrations begin. This will shield you against specific dangers and blueprint the duties of each gathering as an SLA. You should peruse the SLA and guarantee that you comprehend what you are consenting to before you sign. Ensure that you comprehend the duties of the specialist organization, and your own commitments.

\subsection{Reliability}

Enterprise applications are currently so important that they should be solid and accessible to help 24/7 tasks. In case of disappointment or blackouts, emergency courses of action must produce results easily, and for grievous or cataclysmic disappointment, recuperation designs must start with least disturbance. Every part of unwavering quality ought to be cautiously viewed as while drawing in with a CSP, consulted as a feature of the SLA, and tried in failover drills. Extra expenses might be related to the required dimensions of unwavering quality; in any case, the business can do just such a great amount to alleviate dangers and the expense of a disappointment. Building up a reputation of unwavering quality will be essential for broad adoption.

\subsection{Network and Open Access}

The maximum capacity of cloud computing relies upon the accessibility of rapid access to all. Such network, rather like power accessibility, all around opens the likelihood for industry and another scope of customer items. Network and open access to figuring force and data accessibility through the cloud advance another time of industrialization and the requirement for progressively refined buyer items.

\subsection{Interoperability}

The interoperability and movability of data among public clouds and private clouds are basic empowering influences for wide appropriation of cloud computing by the undertaking. Numerous organizations have gained significant ground toward institutionalizing their procedures, information, and frameworks through the execution of ERPs. This procedure has been empowered by adaptable foundations to make single occurrences, or very coordinated associations between examples, to deal with the consistency of ace and exchange 
information and create solid combined data. Indeed, even with these enhanced stages, the speed at which organizations change may in any case outpace the capacity of IT associations to react to these changes. SaaS applications conveyed through the cloud give a low-capital, quick sending alternative. Contingent upon the application, it is basic to coordinate with conventional applications that might be inhabitant in a different cloud or on customary innovation. The excellence for ability is either an empowering agent or a hindrance to interoperability and grants support of the uprightness and consistency of an organization's data and procedures.

\subsection{Integrity}

Shaqrah et al. [21] Integrity related with the check framework against any sort of information misfortune, alteration, as well as harm which caused purposeful or unexpected reasons, for example, harming activities of programmers or unapproved individual both inside or remotely enterprise. In this manner, the web security framework anticipated that would guarantee that information got precisely in the correct way. Regardless of the first reason for losing information honesty, this misfortune will be awful for a web security framework. Last, validness is specifically identified with the procedures of security framework which performs to set up information exchange when begun and where end, in this way attempting to guarantee the information got was truly started where it says it is originating from and sent by the one referenced on its mark. An Enterprise task controlled by complex conventions which may, shockingly, include a few issues the extent that framework security is concerned [22].

\subsection{Monetary Value}

The improvement of cloud computing is predicated on the landing on speculation that accumulates. It appears to be instinctive that by sharing assets to smooth out pinnacles, paying just for what is utilized, and cutting forthright capital interest in sending IT arrangements, the monetary value will be there. There will be a need to mind adjust all expenses and advantages related with cloud computing - in both the long and short terms. Concealed expenses could incorporate help, fiasco recuperation, application change, and information misfortune protection. There will be edge esteems whereby solidifying ventures or consolidating cloud administrations bodes well; for instance, it probably won't be productive or practical to use various self-governing SaaS applications. Each may contract for debacle recuperation program administrations. There is where economies of scale mean these capacities ought to be consolidated in a comparative administration. Application utilization may start with a low volume of exchanges that can be upheld by semi-robotized ace information the board [23]. As utilization grows and interoperability necessities for the business procedure turn out to be increasingly grave, another methodology is required. This advancement might be the most cost-effective approach; in any case, there is a hazard that the business progress costs starting with one arrangement then onto the next may change the expense and advantage condition, and henceforth the arrangement that ought to be utilized.

\subsection{Exiting the data center}

By 2025 about $80 \%$ of ventures will have closed their customary data centers, as indicated by Cappuccio et al. [24] with Gartner. Between the important land, figuring equipment, programming, and security controls, data centers are a noteworthy capital venture. While this may have once been the "cost of confirmation" for most organizations, there are currently increasingly light-footed foundation choices accessible to clients. Be that as it may, the change out of the data center can be hard to design, tedious to execute and can overburden in-house IT groups. Our prescribed procedures way to deal with breaking free of the data center was created from broad involvement with a huge number of arrangements crosswise over ventures. We meet you where 
you are by leading evaluations, enable you to structure your future state, and after that arrangement, facilitate and execute movements, and secure your end-state condition.

\subsection{Virtual machine migration}

Virtualization can give huge advantages in cloud computing by empowering virtual machine relocation to adjust the heap over the data center. What's more, virtual machine relocation empowers hearty and exceptionally responsive provisioning in data centers. Virtual machine relocation has advanced from process movement procedures. Clark et al. [25] called attention to that relocating a whole OS and every one of its applications as one-unit permit to keep up a vital separation from countless inconveniences looked by process level movement approaches and broke down the advantages of live movement of VMs.

Mir et al. [26], the real advantages of VM relocation is to keep away from hotspots; notwithstanding, this isn't direct. As of now, recognizing outstanding burden hotspots and starting a movement does not have the spryness to react to sudden remaining task at hand changes. Additionally, the in-memory state ought to be exchanged reliably and productively, with incorporated thought of assets for applications and physical servers.

\subsection{Political Issues Due to International threshold}

In the cloud computing world, there is changeability as far as where the physical information dwells, where preparing happens, and from where the information is gotten to. Given this inconstancy, diverse security principles and directions may apply. In view of these shifting tenets and controls, legislative issues turn into a component in the appropriation of cloud computing, which is successfully distinguished. For cloud computing to consistently develop into a borderless and worldwide device, it should be isolated from governmental issues. At present, some major worldwide innovative and political forces are making laws that can negatively affect the advancement of the worldwide cloud. For instance, because of the Uniting and Strengthening America Patriot Act, Canada has as of late asked that its legislature not utilize PCs in the worldwide system that are working inside U.S. outskirts, dreading for the secrecy and security of the Canadian information put away on those PCs [27]. Suppliers have been not able assurance the area of an organization's data on a predefined set of servers in a predetermined area. Be that as it may, cloud computing specialist organizations are quickly receiving measures to deal with this issue. For instance, Amazon Web Services as of late reported the Amazon Virtual Private Cloud that enables a business to associate its current foundation to a lot of detached AWS register assets by means of a VPN association. To fulfil the European Union information directions, AWS now enables organizations to convey its Simple DB organized capacity physically inside the EU area. Cloud computing depends on worldwide governmental issues to endure. Envision if the broadcast communications organizations in the United States get their direction and get rid of the present Internet standard of system lack of bias totally. Having information throttled and data sifted conflicts with the essential idea of cloud computing and worldwide learning.

\subsection{Information Lock-In and Standardization}

A noteworthy worry of cloud computing clients is tied in with having their information secured by a specific supplier. Customers may need to move data and applications out from a provider that does not meet their essentials. Regardless, in their present edge, cloud computing structures and stages don't use standard procedures for securing customer data and applications. Therefore, they don't interoperate, and client information are not versatile. The response to this worry is institutionalization. Toward this path, there are efforts to make open measures for cloud computing. The Cloud Computing Interoperability Forum (CCIF) was framed by associations, for example, Intel, Sun, and Cisco to "empower a worldwide cloud computing 
biological community whereby associations can flawlessly cooperate for the reasons for more extensive industry appropriation of cloud computing innovation." The improvement of the Unified Cloud Interface (UCI) by CCIF goes for making a standard automatic purpose of access to a whole cloud foundation. In the equipment virtualization circle, the Open Virtual Format (OVF) goes for encouraging pressing and dissemination of programming to be kept running on VMs so virtual apparatuses can be made versatile - that is, flawlessly kept running on hypervisor of various merchants.

\subsection{Transfigure in the IT Organization}

The IT affiliation will be impacted by cloud computing, as has been the circumstance with other development shifts. There are two measurements to shifts in innovation. The first is gaining the new ranges of abilities to send the innovation with regards to take care of a business issue, and the second is how the innovation changes the IT job. Amid the COBOL period, clients occasionally customized, the desires for the UI fluctuated, and the flexibility of the arrangement was low. Preparing was conveyed in isolated manuals and the client utilized the PC to tackle issues just down predefined ways. With the appearance of fourth-age dialects, jobs inside IT, for example, framework expert and developer, wound up converged into investigator/software engineer, clients began to compose their own reports, and new applications, including operational information stores, information section, and question programs, could be quickly conveyed in weeks. Information Technology's job will change by and by, the speed of progress will affect the selection of cloud innovations and the capacity to break down develop arrangements from promotion to convey genuine incentive from cloud innovation, and the need to keep up the controls to oversee IT hazard in the business will increment.

As per Right Scale [28], Cloud Challenges gets declined by and large in Security, Expertise, and Spend. In 2018, cloud difficulties declined in all cases separated from administration/control, which stayed level. In 2018, skill, security, and spend were all tied for the best test with 25 percent of respondents preferring to each as a critical test. Fig. 4. Portrays the decay of Cloud challenge.

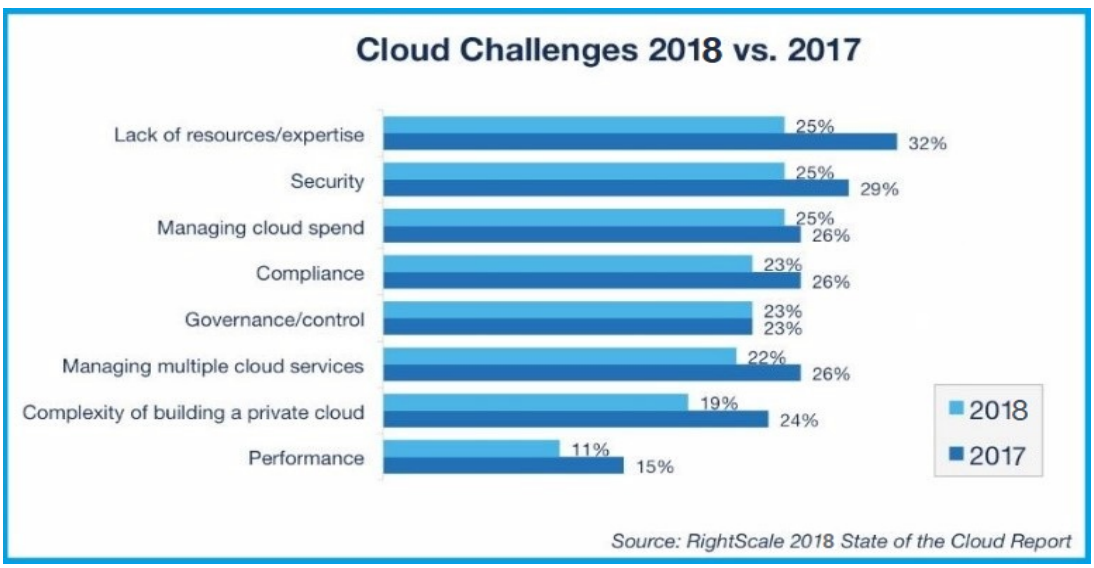

Fig. 4. Cloud challenge declined from the previous year

An absence of expertise/resources for cloud challenge in 2017, was to a lesser extent a test in 2018 with just 25 percent referring to it as a noteworthy worry, down essentially from 32 percent in 2017 . Worries about 
security tumbled to 25 percent versus 29 percent a year ago. Overseeing cloud spend fell just marginally from 26 to 25 percent.

\section{Conclusion and Future Thoughts}

This paper presents an overview of cloud computing paradigm. In any case, the use of cloud computing and how its development based on passing on certifiable motivation to the business. Without a doubt, the cloud is a creative innovation that will change the manners by which people and ventures work, it gives incredible preferences to the associations, enabling them to diminish their it operational expenses. In this paper, we have studied the cutting-edge cloud computing, covering its basic ideas, conspicuous attributes, services and layers of cloud. Regardless of its critical advantages proposed by cloud computing, the present innovations are not sufficiently developed to understand its maximum capacity, many key issues in this space, including protection, information security, information secure, accessibility of administration, disaster recovery, execution, versatility, are just beginning to get consideration from the exploration network. Accordingly, we accept there is yet enormous open door for analysts to make historic commitments in this field and acquire noteworthy effect to their advancement the business. As the improvement of cloud computing innovation is still at a beginning period, we trust our work will give a superior comprehension of the plan difficulties of cloud computing and make ready for further research around there.

We've observed through Right Scale the reduction in challenges related to Cloud Computing since last few years. Hence, we concluded if we've good expertise in an organization, we can minimize the risks and obstacles for embracing Cloud Computing.

To accomplish this at the product frameworks level, we must examine new procedures for assignment of assets to applications contingent upon the nature of administration desires for clients and administration contracts built up among buyers and suppliers.

\section{References}

[1] Zhang, Q., Cheng, L. \& Boutaba, R. (2010). "Cloud computing: state-of-the-art and research challenges", J Internet Serv Appl (2010) 1: 7-18. DOI 10.1007/s13174-010-0007-6

[2] Islam, S., Mouratidis, H., \& Weippl, E. R. (2013). A Goal-Driven Risk Management Approach to Support Security and Privacy Analysis of Cloud-Based System. In D. Rosado, D. Mellado, E. Fernandez-Medina, \& M. Piattini (Eds.), Security Engineering for Cloud Computing: Approaches and Tools (pp. 97-122). Hershey, PA: IGI Global. doi:10.4018/978-1-4666-2125-1.ch006

[3] Takabi, H., Joshi, J. B. and Ahn, G. (2010). "Security and Privacy Challenges in Cloud Computing Environments," in IEEE Security \& Privacy, vol. 8, no. 6, pp. 24-31. doi:10.1109/MSP.2010.186

[4] Al-Mascati, H., \& Al-Badi, A. H. (2016). Critical success factors affecting the adoption of cloud computing in oil and gas industry in Oman. In 2016 3rd MEC International Conference on Big Data and Smart City, ICBDSC 2016 (pp. 187-193). [7460365] Institute of Electrical and Electronics Engineers Inc. DOI 10.1109/ICBDSC.2016.7460365

[5] Mell, P. \& Grance, T. (2011). The NIST definition of cloud computing, National Institute of Standards and Technology, USA, NIST Special Publication 800-145 doi:10.6028/nist.sp.800-145

[6] Bask, I. (2015). Why cloud technology is the smart move right from startup. Entrepreneur. [Online] Available at: https://www.entrepren eur.com/article/24 1914 [Accessed 31 Oct 2018]

[7] Vasiljeva, T., Shaikhulina, S., \& Kreslins, K. (2017). "Cloud Computing: Business Perspectives, Benefits and Challenges for Small and Medium Enterprises (Case of Latvia)". Procedia Engineering, 178, 443-451. doi:10.1016/j.proeng.2017.01.087 
[8] Subashini, S. and V. Kavitha. (2011). A survey on security issues in service delivery models of cloud computing. Journal of Network and Computer Applications [Electronic], 34(1), pp.1-11. doi:10.1016/j.jnca.2010.07.006.

[9] Marston, S., Li, Z., Bandyopadhyay, S., Zhang, J., \& Ghalsasi, A. (2011). Cloud computing - The business perspective. Decision Support systems, 51(1), 176-189.

[10] Iyer, B. and J.C.Henderson. (2010). Preparing for the Future: Understanding the Seven Capabilities of Cloud Computing. MIS Quarterly Executive, 9(2), pp.117-131.

[11] Khan S., Mohiuddin K., Maqbool F. (2017). "Analysis of Paradigm Shift in Cloud-based GIS Systems", International Journal of Advance Research in Science and Engineering, 6(3), pp. 345-354

[12] Nurmi, D., Wolski, R., Grzegorczyk, C., Obertelli, G., Soman, S., Youseff, L., and Zagorodnov, D. (2009). "The Eucalyptus open-source cloud-computing system", in Proceedings of IEEE/ACM International Symposium on Cluster Computing and the Grid (CCGrid 2009), Shanghai, China, pp. 124-131.

[13] Voorsluys, W., Broberg, J. and Buyya, R. (2011). Introduction to Cloud Computing, in Cloud Computing: Principles and Paradigms, ed. by R. Buyya, J. Broberg, A.Goscinski (New York: Wiley, 2011), pp. 1-41

[14] Youseff, L., Butrico, M. and Silva D. D. (2008) Toward a unified ontology of cloud computing, in Proceedings of the 2008 Grid Computing Environments Workshop, pp. 1-10.

[15] Armbrust, M., A. Fox, R. Griffith, A.D. Joseph, R. Katz, A. Konwinski, G. Lee, D. Patterson, A. Rabkin, I. Stoica and M.I Zaharia. (2010). A view of cloud computing. Communications of the ACM [Electronic], 53(4), pp.50-58.

[16] Avram, M. G. (2014). "Advantages and Challenges of Adopting Cloud Computing from an Enterprise Perspective". Procedia Technology, 12, 529-534. doi:10.1016/j.protcy.2013.12.525

[17] Buyya, R., Pandey, S. and Vecchiola, C. (2009). "Cloudbus toolkit for market-oriented cloud computing", in Proceedings 1st International Conference on Cloud Computing (CloudCom 09), Beijing, 2009, pp. 3-27

[18] Gonzalez, N., Miers, C., Redigolo, F., Carvalho, T., Simplicio, M., Naslundy, M., \& Pourzandiy, M. (2012). A quantitative analysis of current security concerns and solutions for cloud computing. Escola Politecnica at the University of Sao Paulo (EPUSP), Sao Paulo, Brazil.

[19] Mazzarol, T. (2003). A model of small business HR growth management. International Journal of Entrepreneurial Behaviour \& Research, 9(1), 27-49.

[20] Feltham, T. S., Feltham, G., \& Barnett, J. J. (2005). The dependence of family businesses on a single decision-maker. Journal of small business management, 43(1), 1-15.

[21] Shaqrah, A. (2016). Cloud CRM: State-of-the-Art and Security Challenges, International Journal of Advanced Computer Science and Applications, Vol. 7, No. 4, pp. 39-43

[22] Shaqrah, A. (2011). "The Influence of Internet Security on E-Business Competence in Jordan: An Empirical Analysis", International Journal of business data communications and networking, Vol 7, No.4

[23] Zhang J, Bandyopadhyay S, Piramuthu S. (2008). Real option valuation on grid computing, Decision Support Systems 46 (1) 333-343

[24] Cappuccio, D. (2009). 03 - Best Practices in Data Center Consolidation [Online] Available at: https://www.gartner.com/doc/1489538?ref= mrktg-srch [Accessed 17 Nov 2018]

[25] Clark C, Fraser K, Hand S, Hansen JG, Jul E, Limpach C, Pratt I, Warfield A (2005) Live migration of virtual machines. In: Proc of NSDI

[26] Mir, I. A. \& Raina CK., (2017). "Cloud Computing and its Research Challenges", International Journal of Engineering Science and Computing, vol.7, no.4, pp. 6501-6506.

[27] Mather T., Kumaraswamy S., Latif S. (2009). "Cloud Security and Privacy: An Enterprise Perspective on Risks and Compliance”, O'Reilly Media, 2009 
[28] Weins, K. (2017). Cloud Computing Trends: 2017 State of the Cloud Survey [Online] Available at https://www.rightscale.com/blog/cloud-industry-insights/cloud-computing-trends-2017-state-cloud-surve y [Accessed 28 Dec 2018].

[29] Khan, S. (2019). "Cloud Computing Paradigm: A realistic option for Business Organizations - A Study", Journal of Multi Disciplinary Engineering Technologies, 12(2), pp. 85-97.

\section{Author' Profile}

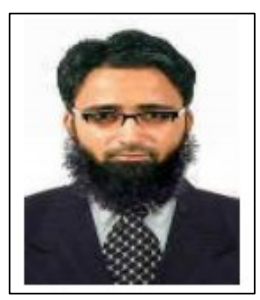

Shafat Khan is an IT faculty working in COMPILER - Institute of Computer Science in the Kashmir valley. He delivers scheduled lectures to Post Graduate (PG) and Undergraduate (UG) students. He has completed Doctorate in Computer Science in 2018 from Himalayan University, Itanagar, India. He has also received the Master's degree in Computer Applications (MCA) from SRM University, Chennai in 2011. He has more than 7 years of teaching and administrative experience. His area of research includes but not limited to Geographic Information System (GIS), Cloud Computing, Big Data analytics, Machine Learning, Artificial Intelligence.

How to cite this paper: Shafat Khan,"Cloud Computing: Issues and risks of Embracing the Cloud in a Business Environment", International Journal of Education and Management Engineering(IJEME), Vol.9, No.4, pp. 44-56, 2019.DOI: 10.5815/ijeme.2019.04.05 